\title{
LA CIUDAD ENFERMA
}

José Manuel Orozco Garibay*

\section{Introducción}

\section{Los libros son enormes cartas escritas} para la gente. Son cartas que tienen un autor, siempre. El autor representa el papel de una persona que está preocupada. Por eso envía una carta a sus semejantes. Tiene un mensaje escondido en su cabeza. Así, el autor trata de que su mensaje llegue a otros.

En los viejos tiempos las cartas se escribían literalmente a mano. Con una hoja de papel (o algo que hacía la función de una tabla con letras en orden alfabético, ya sea que se llame códigos a esas tablas, piedras, maderas talladas o papel primitivo), el objetivo era llegar a otras mentes. De mente a mente, el propósito de escribir era hacer posible lo que parece imposible. Una mente debe alcanzar otra mente. Lo que está en la mente debe encontrarse en la mente de otro. Aunque el mensaje llegue a otro de diferente manera, el mundo en la mente del escritor también debe estar en la mente del lector. La asunción de que lo que tiene en mente el autor de la carta llegue a la mente del lector, tal y como lo pensó el autor, es un reto. ¡Establece que un mundo pase de una mente a otra por medio del acto de leer! Sin embargo, el acto de leer no tiene sentido alguno sin el acto de escribir. El par "escribir-leer" se convierte en el orden necesario para que exista lo que se llama "mensaje".

* Departamento Académico de Estudios Generales, ITAM. 


\section{Cartas, mensajes}

Un mensaje debería poder ser entregado. De otro modo no sería un mensaje en absoluto. La mera idea de que hay un mensaje se relaciona con la urgencia que contiene. Esto es así porque en el mensaje hay un código que debe ser descifrado. La emisión del mensaje (quien lo manda, el autor original de la carta) pretende que el receptor entienda el código escondido en el mensaje. El proceso completo de urgencia consiste en la necesidad de entregar un código a los otros. ¿Por qué esta actitud tan extraña es importante? ¿Por qué hablar de urgencia cuando se envía un mensaje? Claramente, el mensaje es importante por la disposición altruista que significa. Representa la necesidad de hacer mejores personas a los otros mediante la lectura del mensaje. Cuando hay una lectura, hay una idea común del mundo compartido. El proceso de compartir el mundo con otros construye la hermandad de hombres y mujeres. Esta es la condición básica para tener una vida en común. Significa poder vivir bajo el paraguas del mismo mundo que autores y lectores habitan, el mundo donde existen. La existencia no es el simple hecho de ser ahí. La existencia es algo más que el instante de ser ahí. La existencia como abierta al mundo se refiere no solamente al instante de ser ahí, sino a la experiencia de ser-juntos. Ser-juntos en el mismo mundo se refiere a la existencia de una red de relaciones entre la gente. Uno se relaciona con el otro ya que es parte del mundo compartido cabe al cual aparece la existencia. Solo existimos en el marco de mundos compartidos, de otro modo no se concibe el hecho de existir.

\section{La humanitas}

La idea de la humanitas como la entendió Cicerón fue una consecuencia del hecho de ser alfabetizado. Según esta concepción, el analfabetismo significa que una persona no es propiamente una persona. Podría decirse que aquellos que eran incapaces de hablar y leer no eran considerados parte de una sociedad civilizada, en el sentido humano. Ser humano tiene que ver con el hecho de haber sido humanizado. La posibilidad 
de ser humano pasa por el registro de ser capaz de leer cartas escritas en un lenguaje.

La filosofía une tanto a amigos como amantes en el acto de escribir de un modo especial. La escritura filosófica es contagiosa y hace que el amor y la amistad se tornen reales en el mundo. Dice Sloterdijk:

El hecho de que la filosofía escrita haya sido capaz de conservarse como un virus contagioso, comenzó hace 2500 años y continúa hasta nuestros días, y debe todo su éxito a la capacidad de hacer amigos a través de los textos. ${ }^{1}$

De generación en generación los libros vienen y van. Es claro que los trabajos de Platón llegaron a Roma de una generación a otra. Los griegos no eran romanos, obviamente. Pero los romanos conservaron muchas características de los griegos. La razón es que los romanos leían textos escritos por los griegos. La tradición oral es sumamente importante; es necesario que la gente viaje de un lugar a otro llevando consigo paquetes de creencias que entregan, donan, a otras comunidades. Conforme pasa el tiempo, las tradiciones sufren transformaciones que conservan algo del pasado. El pasado se conserva, pero al mismo tiempo es superado en formas nuevas, costumbres, disposiciones y creencias diferentes. Es muy importante que los romanos hayan tenido esas visitas a través de los años. Como imperio, los romanos hicieron guerras que incorporaron a sus propios sistemas de creencias los modos de vida de los pueblos conquistados. Por medio de guerras, viajes, lectura de textos, viejas tradiciones se volvieron presentes en la vida romana.

\section{Cartas e interpretación}

El problema que enfrentamos es que necesitamos una interpretación de los libros. Los libros dicen algo. Se supone que hay un contenido en los libros, y ese contenido no puede ser alterado. Así, si hay un significado tiene que ser un significado único. Un acercamiento objetivo a un

${ }^{1}$ Peter Sloterdijk, Normas para el parque humano (Madrid: Ciruela, 2008), 20. Muchas de las ideas de este ensayo derivan de las reflexiones de Peter Sloterdijk en esa obra. 
libro implica que el libro puede ser entendido en sus propios términos. Lo que entiende el lector es justamente lo que el escritor dijo. Aún más, lo que está escrito en el libro concebido como carta es lo que el lector comprende. Empero, una interpretación solamente es un acercamiento. No hay manera de rechazar el hecho de que una interpretación trata de captar el sentido del libro. Por ende, el mensaje se entiende como "entregado". Los romanos entendieron lo que los griegos decían en sus cartas. Sin embargo, es falso que dicho entendimiento haya sido perfecto. Una copia es solamente una mera copia. Esto significa que una copia no es un trabajo original en sentido alguno.

La interpretación de una carta nunca dirá lo que el autor realmente dijo. Asumimos que un mensaje trata de crear un mundo común donde habitar. Entonces, la idea de que hay diferentes interpretaciones de una carta nos lleva a ver que no puede haber un mundo común. Aproximaciones al mundo compartido nos ayudan a entender las ideas de los demás, de modo que una suerte de amistad y amor hacen posibles las relaciones humanas. La red de las relaciones humanas es una red humana de acuerdo con el esfuerzo por compartir una suerte de experiencia común del mundo.

Peter Sloterdijk dice que siempre será el caso que nos topemos con fracturas y grietas en el amor y la amistad:

Es seguro que los autores griegos se habrían sorprendido de saber qué clase de amigos aparecerían algún día procurando leer sus cartas. Una regla para la cultura alfabetizada es que los emisarios no pueden prever los receptores que tendrán. Sin embargo, los autores no renunciaron a la aventura de hacer circular sus cartas escritas dirigidas a amigos no identificados. Sin la codificación de la filosofía griega en rollos transportables de papel, los objetos postales que llamamos tradición jamás se habrían enviado. ${ }^{2}$

Es claro que una carta necesita emisarios y receptores. Enviadores y lectores, copistas e interpretaciones. Por tanto, aquellas cartas podrían recorrer distancias largas en el tiempo y el espacio. Una carta enviada en el siglo IV a.C. podía alcanzar Roma en el siglo III d.C., pero al mismo tiempo, la distancia que cubrían en esos tiempos los mensajeros

${ }^{2} I b i d ., 21$. 
de Atenas a Roma era inmensa, y aunque sigue siendo la misma en sentido geográfico, el transporte cambia. Seguro que en este siglo XXI alucinante, la carta llega en un segundo, en un nanosegundo. No se sabe si la velocidad en la entrega hace mella en la interpretación. Compartir el mundo requiere tiempo, cierta calma reflexiva. La inmediatez puede dañar el sentido, modificarlo. En todo caso, las distancias y los tiempos deben ser suficientes para alcanzar a toda la Europa habitada de hoy. En su momento, para que la carta de Platón llegara a toda Europa se necesitaron siglos. El interés en que una carta llegue a más gente deriva del interés en el humanismo.

El complejo proceso que exploramos enseña que tiene que haber un escritor que jamás sabrá quién será su próximo lector receptor. Envía la carta sin saber quién será el receptor que lea la carta enviada. Enviar una carta constituye el modelo ejemplar del amor, pues el autor envía su mensaje con la esperanza de que llegue a todos. Y si no alcanza a todos, el autor de la carta espera que su mensaje llegue a un lector en algún lugar. El texto escrito no solo tiende un puente telecomunicativo entre amigos que viven en tiempos diferentes, sino que además entabla un proceso de seducción. El libro es una invitación a amar, y el amor se produce en el momento en que alguien lee. La persona que escribió la carta estará presente entre los que leen porque ellos reciben una carta concebida como regalo, como donación.

\section{Gramática y humanismo}

El fantasma comunitario que está en la base del humanismo podría referir o apuntar a una sociedad literaria cuyos miembros se descubren a sí mismos leyendo mundos comunes, compartiendo actitudes, manteniendo diferencias en sus sistemas de creencias; pero, sobre todo, se conciben como miembros apasionados e inspirados por los remitentes.

Mucho tiempo después de los primeros remitentes de la era grecorromana, en la Edad Media, el conocimiento de la gramática llegó a ser un asunto de gran relevancia. En el momento en que se constituyó el Estado-nación, la capacidad de una persona para escribir de acuerdo con 
las reglas de la buena gramática se concibió como una cualidad propia de la élite. Sloterdijk sostiene que saber gramática era visto como una suerte de magia. De la palabra "gramática" deriva glamour: un hombre que sabe cómo leer y escribir es capaz de hacer muchas cosas que el vulgo no puede. Una persona que sabe gramática es humana en el sentido de que está humanizada. La secta de las personas humanizadas difiere de aquellas que no están humanizadas porque no son capaces de leer y escribir. Una actitud mística apareció, una suerte de cábala que trata de descubrir los secretos del autor del mundo.

En el siglo XX, las sociedades se especializaron en preparar escritores, lectores, hacedores de grandes cartas. Los Estados nacionales burgueses se consolidaron en su carácter laico con el objeto de normar a la sociedad política. La regla principal es que la mayoría de la gente debe ser cultivada y alfabetizada. El propósito es lograr que la mayoría lea cartas escritas por otros, siempre desde un espíritu laico. Sloterdijk señala que las sociedades modernas son ficciones eficientes de lectores que leen los mismos textos o cartas. Así, en la sociedad moderna las personas pueden ser amigas. Por eso es que una sociedad violenta es una sociedad de iletrados.

El servicio militar obligatorio para los hombres jóvenes, que leían a los clásicos en las escuelas, dio lugar a una sociedad armada y cultivada. Con todo, no existe una regla literaria que nos diga cómo leer y entender un texto. Actualmente, sentimos nostalgia por esas escuelas, esas academias militares, esas sociedades conservadoras, donde todos desarrollaban el sentido esencial de querer leer. Había un código, un canon, un modo "normal" de leer y escribir. Había incluso un modo natural de actuar como hombres y mujeres. Hoy, extrañamos eso, pues no existe ya un código o canon común para que todos lean y escriban.

\section{Humanismo, lectura y medios de comunicación}

El humanismo de la lectura se desarrolló entre 1789 y 1945. Poderosos maestros que habían estudiado a los clásicos fueron escritores de cartas fundamentales para la vida en comunidad. Las naciones burguesas fueron 
productoras tanto de textos epistolares como literarios (cartas literales y cartas literarias). Había autores comunes que la gente adoptaba, asumía, incorporaba, con el objeto de vivir homogéneamente.

Los llamados medios masivos de comunicación aparecieron con la radio (1918) y la televisión (1945), y a principios de la era de la sociedad posmoderna entraron en escena los medios digitales. Formas como WhatsApp, Facebook, Instagram, correo electrónico y las llamadas aplicaciones para redes de contacto inmediato volvieron inútiles las cartas. La gente dejó de mandar cartas. Es la edad de la informática, que es justamente una edad deshumanizada.

Es peligroso usar 'pos-' o 'tardo-' como prefijos de “moderno" en relación con la vida social y cultural. Da miedo tener que admitir que ya no producimos más cartas. La era del humanismo toca a su fin porque la actividad epistolar está muerta. Dice Sloterdijk:

La edad del humanismo moderno como modelo escolar y educativo ha pasado porque es imposible mantener la ilusión por más tiempo en torno a macroestructuras políticas y económicas organizadas de acuerdo con la clase de modelo de las sociedades literarias. ${ }^{3}$

Después de la Segunda Guerra Mundial, hacia 1950, la gente trató 173 de leer de nuevo. Muchos libros que hablaban de la existencia, del absurdo, de la paz, incluso del amor, y una fuerte necesidad de denunciar el hecho bárbaro de matar en la guerra, hicieron posible creer que se formaría una sociedad de jóvenes goethianos en contraste con la sociedad de jóvenes hitlerianos.

Las universidades hicieron un gran esfuerzo para volver a los clásicos. Cada estudiante debía leer nuevas ediciones de los autores romanos, para cultivar una inspiración cristiana que fundamentara la civilización occidental. Sin embargo, el humanismo fue una reacción contra la barbarie humana. Uno se pregunta por el futuro de la humanidad, pero en el fondo de la cuestión uno quiere saber si podemos controlar las formas salvajes de los hombres contemporáneos. En nuestros días, los bárbaros

${ }^{3}$ Ibid., 29. 
son los Estados fallidos. Son Estados que ejercen una poderosa influencia de imperios con pretensiones belicosas. ${ }^{4}$ Así, actualmente la disposición humanista trata de domesticar a los hombres en lugar de crear lectores conscientes con capacidad crítica. En sus comienzos, los seres humanos solían escribir cartas enviando mensajes de amor a sus semejantes. Empero, con el tiempo, y sobre todo en nuestro tiempo, de lo que se trata es de domesticar las disposiciones bárbaras del hombre posmoderno.

Es claro que las actitudes bárbaras han sido parte de la condición humana. No todos los hombres leían en la era de Roma. El tiempo de pan y circo para el pueblo en el Coliseo fue expresión de la brutal necesidad de distraer a la gente por medio de la violencia como espectáculo. Dice Sloterdijk:

En los estadios estruendosos de toda la era mediterránea, el Homo inhumanitus desinhibido pasaba momentos de placer que no habían sido vistos con anterioridad, e incluso después. Durante la época del imperio romano, la provisión de fascinaciones brutales para las masas se convirtió en una técnica necesaria del gobierno cuya estructura se expandió y perfeccionó como normal: algo de la experiencia gozosa del pan y circo se ha conservado hasta nuestros días en la mente de todos nosotros. ${ }^{5}$

\section{De una carta sobre el humanismo (Heidegger)}

En 1946 Heidegger envió una carta a sus amigos. Una carta para ellos después del belicismo de ese tiempo. Heidegger el germano fue el llamado "amigo de los nazis". Al reflexionar en torno a su condición como ser humano, se vio en la necesidad de redactar esa carta. No fue una carta que buscara promover la comunión del público general con los clásicos. Fue una carta abierta dirigida a sus amigos, una carta filosófica. Sabía que tenía que hablar con cuidado, con voz temblorosa, buscando

${ }^{4}$ Ese es el papel que desempeña Estados Unidos desde su fundación, y con diversos matices sigue determinando intervenciones, controles, desplazamientos y políticas que afectan a las sociedades más civilizadas. Lo bárbaro de ese país es su tono imperial y lo que surge como consecuencia de eso. Por más que se hable del alto grado de civilidad que puede haber en su sociedad.

${ }^{5}$ Ibid., 34. 
algunos amigos remanentes. Era necesario construir nuevas bases de amistad. Así que se trataba de una carta escrita por un extranjero, enviada con más precisión a un amigo francés. Tomando en cuenta que Francia había sido invadida por los alemanes en la Segunda Guerra Mundial, la carta al amigo francés es simbólica.

Es pertinente formular algunas preguntas. ¿Fue esta carta una nueva forma de enviar mensajes? ¿Fue esta carta el mejor camino para hacer posible compartir el mundo? ¿Representó una nueva forma de hacer filosofía más allá del humanismo nacionalista? Es más, ¿fue esta carta un rechazo de los nacionalismos? Cuando escuchamos en nuestros días que los políticos regresan a los nacionalismos recalcitrantes que claman por cerrar fronteras, rescatar valores como la sangre y lo nacional, algo dentro de nosotros comienza a cimbrarse. Esto es así debido al hecho de que recordamos que una carta debería ser enviada a nuestros amigos extranjeros en el mundo abierto. En una sociedad de fronteras cerradas, la carta no podría ser distribuida en otras latitudes, fuera del territorio nacional.

La carta fue enviada a Jean Beaufret, quien hizo una pregunta en francés: “Comment redonner un sens au mot 'humanisme'?". Se podría traducir la frase como la comprende Heidegger. Primero, Beaufret cree que la palabra "humanismo" existe, de modo que tiene que haber algo llamado "humanismo". El humanismo existe. Segundo, el sentido de la palabra está perdido. La idea es proporcionar un sentido al término "humanismo", porque en nuestro tiempo ese sentido está perdido. Sin embargo, Heidegger piensa que debemos abandonar la palabra "humanismo" para pensar con propiedad.

La tradición suponía que había un sentido de la palabra que reflejaba las relaciones entre los hombres y su propia representación del humanismo. Por ende, ser hombre o mujer significaba ser humano en el sentido humanista. Después de la violencia y brutalidad de la conducta humana, es claro que los hombres siempre fueron hombres. En el momento en que un hombre pelea contra otro hombre, la idea del humanismo se destruye. El hombre agresivo se destruye a sí mismo tan pronto como destruye a otro hombre, a cualquier otro hombre. El problema se 
centra en la idea del hombre. Entonces la pregunta es: ¿Qué significa ser hombre? ¿Qué significa ser mujer? ¿Qué significa lo humano de hombres y mujeres? En general, la gran cuestión planteada de otro modo es: ¿Qué significa ser humano en una sociedad inhumana? El cristianismo, el marxismo y el existencialismo fueron tres modos filosóficos de entender la palabra "humanismo". Pero ninguno de esos tres relatos cuestiona la esencia de lo que es "humano".

Heidegger argumenta que debemos concentrarnos en pensar la esencia de la idea del hombre. Como punto de partida, Heidegger sostiene que deberíamos renunciar a ser hombres ordinarios. Un hombre que cree que ser humano significa ser un animal racional, animale rationale, cree que ha captado la esencia de lo humano. Sin embargo, no hay una perspectiva biológica para expresar la esencia del hombre. No existe una aproximación zoológica para eso. Parece ser que no hay manera de entender la esencia del hombre incluso si un componente espiritual se agrega a la mera dimensión de los aspectos biológicos y zoológicos del ser humano. La unión del concepto de animale (animal) con el concepto de rationale (racional) tiene que ser anulada.

Heidegger alcanza el nivel de la histeria cuando dice que estamos más cerca de Dios que los demás animales. Dice Sloterdijk:

El núcleo efectivo de este pathos anti-vitalista descansa en el conocimiento de lo humano como diferente de lo animal en un sentido ontológico. No hay un sentido específico o genérico bajo cuyo concepto pueda el hombre comprenderse como un animal con un plus cultural y metafísico. Aún más, la forma más propia de ser humano difiere tanto en su esencia como en sus aspectos ontológicos del resto de los vegetales y animales, ya que el hombre tiene un mundo mientras los vegetales y los animales están limitados — de acuerdo con Heidegger- a estar en tensión en sus respectivos ambientes. ${ }^{6}$

Así, el hombre enfrenta el mundo. El hombre como ser humano es el ser del lenguaje que describe el mundo. El ser causa problemas al hombre, de modo que el hombre es el pastor del ser. El hombre debe conservar el ser en el sentido de cuidar el ser. Existe un círculo que va del

${ }^{6}$ Ibid., 45. 
hombre al ser y del ser al hombre. Y es el lenguaje el camino para llegar al ser. Heidegger cree que los humanos son seres que cuidan del ser. Esta es la razón por la cual los seres humanos son seres dotados de lenguaje. El hombre es el ser que habita el lenguaje en tanto que casa del ser. Será un problema constante interpretar la proposición "el lenguaje es la casa del ser". Sin embargo, Heidegger se refiere al hombre como el ser que vive en el lenguaje, dentro del lenguaje, como medio para alcanzar y cuidar el ser. El lenguaje como casa del ser implica que el ser habla, el ser trata de decirle algo al hombre. Debe haber una gramática del ser. Sin embargo, el ser es indecible, ya que uno solamente puede decir que el ser es lo que es, ser es ser. La idea es que en el silencio uno puede escuchar y sentir la presencia del ser. Todos los esfuerzos por preservar el ser pasan por el lenguaje. Sin embargo, el lenguaje enmudece ante el Ser.

\section{¿A favor o en contra del humanismo?}

Heidegger no está contra el humanismo. Rechaza la asunción de que uno puede conocer la esencia humana que los humanistas pretenden conocer. Sostiene, en cambio, la idea de que la existencia humana consiste en el mero hecho de hacer posible que un hombre sea amigo del mundo de otro hombre. El proceso de traspaso de la pedagogía a la ontología nos hace entrar en otra dimensión del humanismo: no necesitamos conocer la esencia de lo humano; es incluso imposible que haya una esencia humana. Lo único que podemos saber es que el hombre es el pastor del ser. Sin embargo, si hay una esencia del ser humano, dicha esencia es la del ser que escucha al ser. Conservar el ser equivale a permanecer en silencio.

Por tanto, Heidegger piensa que ha ido más allá del humanismo clásico. La relación entre el hombre y el ser es más fuerte que cualquier otra relación que el humanismo pudiera explicar. La relación ontológica básica del hombre con el ser es una relación de amistad. El hombre contiene al ser. El hombre observa el ser. Al hacerlo así, el hombre permanece en silencio ante el ser. Es una disposición mística que jamás se encontrará en el humanismo. 
No estando ni a favor ni en contra del humanismo, Heidegger va más allá del humanismo. Heidegger solo abandona el humanismo como camino para capturar la esencia de lo humano, y encuentra en la relación ontológica del hombre con el ser una amistad silenciosa en la que el hombre es el ser que cuida al ser y escucha lo que el ser dice. El ser del hombre contiene en su ser el pensar el ser, observarlo, saber del ser. El cuidar el ser místicamente constituye el modo de ser del hombre. No su esencia ni tampoco la esencia del ser. El ser que cuida el ser se abre al mundo del otro. Y eso es lo humano. Mas no la esencia de lo humano. El problema de la esencia del humanismo que define al hombre como humano es algo que Heidegger deja de lado.

Ante la barbarie humana, el cuidado del ser es el problema que ha de ocupar al hombre. Y al hacerlo así, la amistad del hombre con el ser determina el modo más peculiar del existir del hombre. En silencio. Solo en silencio se abre el ser al hombre.

\section{Heidegger como hegeliano: un enfoque fascista}

Al guardar silencio, el ser-ahí escucha al ser. El ser habla en el sentido de que, por medio del lenguaje, el hombre trata de entender lo que el ser dice. La primera idea de este proceso de silencio tiene que ver con aceptar que el hombre ha olvidado el ser. Hay en curso una destrucción del ser que se puede apreciar en la deforestación, la contaminación, las grandes concentraciones de gente. Por ende, más allá del humanismo clásico, Heidegger pretende estar más cerca del ser. En silencio el ser habla. El ser dice mucho al hombre silencioso. Hay un espacio de reflexión en el silencio que es compatible con una contención estática de los impulsos. Así que es mucho mejor ser el pastor del ser antes que un lector de textos clásicos, antes que enviar cartas a un selecto grupo de domesticadores.

Heidegger quisiera que hubiese un fuerte grupo de amigos. Incluso si es un grupo pequeño capaz de expresar el ser que habla a través de ellos, los amigos. De manera hegeliana, el ser habla a través de los hombres que cuidan el ser. Por lo tanto, el ser se conserva a sí mismo a través de los hombres que lo cuidan. Estar en silencio ante el ser significa que el 
ser habla acerca de sí mismo por medio del silencio de los seres que cuidan del ser. Dice Sloterdijk:

Él (Heidegger) quisiera abrir el proceso de hacer amigos en el que él no fuese recibido como un clásico o como uno entre muchos autores; sería mejor comenzar haciendo que la gente, considerando un número reducido de personas - como es natural- dotadas de idea e intuición, pudiese tomar conciencia de que es el ser en sí mismo el que habla de nuevo por medio de él (Heidegger), como el mentor de la cuestión acerca del ser. ${ }^{7}$

La idea es que el ser habla, a través de Heidegger, a sus amigos en tanto que mentor de la cuestión acerca del ser. Así, el ser pregunta por sí mismo a través de Heidegger. La autoridad que puede hablar del ser proviene del ser. Es por eso que Heidegger impone silencios y murmullos como medios para acercar a los amigos, quienes se comportarán como pastores del ser en una actitud de contemplación y ensimismamiento. La simple idea de este grupo críptico de vecinos del ser nos hace pensar en una especie de secta religiosa de pastores. Heidegger rechaza el humanismo para reforzar el sentido de la preservación del ser. Los hombres no son dueños de la casa que habitan, sino vecinos del ser. Los hombres ni siquiera son inquilinos de la casa del ser. Heidegger cree que los humanismos promueven la subjetividad propia de egoístas explotadores de la existencia. Todo lo que existe está destruido por los hombres como resultado de diferentes tipos de humanismo.

A mediados del siglo XXI, el bolchevismo, el fascismo, el americanismo, constituyeron tres maneras de expresar la violencia antropocéntrica. La idea ha sido controlar el mundo bajo la apariencia de una actitud humanista. Dice Sloterdijk que Heidegger considera el fascismo como una mezcla de humanismo con bestialidad.

Sloterdijk plantea la cuestión que debemos responder:

[...] Si los juegos pastorales ontológicos de Heidegger — que siempre han sido extraños y chocantes - son anacrónicos en nuestros días, en cualquier caso, [...] [los juegos ontológicos pastorales] han sido capaces de articular correctamente la cuestión de la época: ¿Qué va a domesticar

${ }^{7}$ Ibid., 48. 
a los hombres si el humanismo falla como escuela de domesticación de los hombres? ¿Qué domesticará al ser humano después de todos los experimentos que se han hecho con el objeto de educar a la especie humana? Dado que es aún incierto quién educa al educador, ¿cuál es el propósito de la educación? ${ }^{8}$

Tiene que haber una historia de la serenidad. Así, podemos entender la mente abierta del hombre hacia el mundo, y al mismo tiempo, la capacidad del hombre para adaptarse al mundo. También necesitamos una historia del proceso social de domesticación de personas, de manera que los seres humanos recuerden que son parte del todo. El animal-sapiens desciende del Homo sapiens. De acuerdo con esto, hay un proceso de humanización que evoluciona de los mamíferos prematuros humano-vivientes hacia animales más inmaduros. Ocurrió una revolución que transformó al recién nacido a nivel biológico al plano del arribo-al-mundo. Tanto el ser-ahí ontológico como el ser-en-el-mundo quedaron fuera de una explicación antropológica en lo que se refiere a su ser. Existe una falta de comprensión de la idea del arribo-al-mundo. La idea de la perpetua inmadurez de la naturaleza humana significa que el arribo-al-mundo ha sido un proceso en el que el sentido más propio de lo humano se tornó real.

Fallar como animal empuja al hombre a salir de su ambiente, de modo que sea capaz de experimentar el sentido ontológico del mundo. El esfuerzo por satisfacer las demandas de la existencia hizo posible para los seres humanos ser humanos en tanto que animales fallidos. Como dice Sloterdijk, los humanos son seres-en-el-mundo como resultado del movimiento que hace que los humanos habiten el mundo y se expongan como seres. El sentido del peligro es el sentido más humano. Los humanos son seres humanos lactantes que llegan a ser seres mundanos.

Claramente, los humanos entran en el mundo por medio del lenguaje. El ser mundano es un ser-en-el-mundo en la medida en que los seres humanos habitan el mundo desde el lenguaje. Esta es la razón por la que Heidegger llamó lenguaje a "la casa del ser". De otra manera, los humanos serían psicóticos. ¿Qué sería lo humano del ser del hombre?

${ }^{8}$ Ibid., 52. 
Heidegger no responde, pero sugiere todo. Es el ser cuyo ser consiste en ser el pastor del ser, y en tanto que cuida al ser habita el lenguaje que es la casa del ser abriendo-el-mundo.

\section{Ciudades, calles, vidas sedentarias}

\section{Dice Sloterdijk:}

Tan pronto como los hombres en su calidad de hablantes viven juntos y en grandes grupos, y que ellos se ligan tanto a casas de lenguaje como construyen casas, ellos se someten al campo de fuerzas de las formas sedentarias de vida. A partir de ese momento, los hombres no solo se permiten a sí mismos ser protegidos por sus lenguajes, sino que ellos son domesticados en sus casas, por el hecho de habitarlas. ${ }^{9}$

La domesticación de los animales comienza. La coexistencia de los hombres y los animales no ha sido descrita con propiedad. Algunos filósofos han hablado de los animales, de los hombres, del habitar en casas, de los albergues, pero la compleja relación biopolítica entre los hombres y los animales es a la vez extraña y oscura. Por lo tanto, la idea del mero entendimiento de la esencia de esa compleja relación revela el misterio de que haya una relación entre hombres y animales. ¿Hay propiamente hablando una relación entre hombres y animales? ¿Se pueden relacionar unos con otros? Puede tratarse de un simple proceso de domesticación, pero no de una relación entre hombres y animales. Los dos polos no se relacionan. No es, seguramente, una relación basada en la equidad, aunque tanto los hombres como los animales son animales. La base común de la relación sería la animalidad de hombres y animales. Sin embargo, el núcleo de la relación permanece desconocido. Al menos, es incognoscible desde la perspectiva de un animal.

Vivir en un hogar (estar en casa), da lugar a muchas teorías acerca de conservar limpia la casa, mantener la división del trabajo, y las demás obligaciones domésticas. En la Antigüedad se definía la relación entre

${ }^{9}$ Ibid., 57. 
los hombres con la idea de tener una casa y una ventana desde donde mirar. Se trataba de una relación contemplativa. Pero en nuestros días, podríamos hablar del trabajo como la relación fundamental entre los hombres y su hogar. Trabajan para tener casa, ventana, contemplar. Entre todos construyen casas.

Sin embargo, es claro que la idea de un pastor que habita una casa como su hogar es algo que cambia desde el momento en que los hombres tratan de construir casas viviendo en ciudades. Al construir imperios, los seres humanos pelean entre sí. Choques y enfrentamientos comienzan también cuando se debe tomar la decisión acerca de la construcción de esas casas. ¿Quién va a construir la casa? ¿Cómo disponer del agua? ¿Cómo distribuir el agua entre todas las casas? Pleitos entre políticos, constructores, pobladores, vecinos, expresaron el carácter sedentario de la vida. Nietzsche ha señalado ese peligro en Así habló Zaratustra al referirse a la virtud. Nietzsche dice que Zaratustra camina y ve una serie de casas, y pregunta: ¿Qué significa tener estas casas? [...] ¿Qué significa tener estas recámaras, estas puertas? ¿Pueden los machos entrar y salir? Zaratustra respondió: ;Todo se ha vuelto más pequeño! Los hombres viven de acuerdo con su virtud y felicidad. Los hombres son justos, redondos, amables, como granos de sal. La felicidad de los hombres se llama "resignación". Los hombres están domesticados, son modestos, pacíficos, y el lobo bravo se ha convertido en un perro doméstico.

\section{Nietzsche y la cultura}

Nietzsche rechaza la cultura humanista porque los hombres modernos están educados para ser articulados, cándidos, creyentes, sometidos a los códigos de domesticación que obedecen en tanto que masas dóciles. Es necesario denunciar la domesticación de los hombres por medio de los valores. Hay entrenadores y programas para entrenar hombres. Existe una diferencia entre los humanistas y los superhumanistas. Nietzsche no promueve los instintos animales en contra de la razón para evadir lo espiritual en beneficio de lo animal. La idea del superhombre se refiere a un hombre que vive en el presente considerando los milenios previos a su llegada. La producción de hombres contemporáneos es el 
resultado del entrecruzamiento de las relaciones humanas, de las mezclas de sangre, de la domesticación y la educación, que se ha vuelto invisible. Bajo la máscara de la escuela hay un proyecto de domesticación. Sin embargo, la mera idea de domesticar implica algo humano. Los monjes y los paulinos (seguidores de San Pablo) domesticaron a los humanos para convertirlos en perros virtuosos en lugar de lobos, y como resultado, en pocas generaciones se concretó el proceso de entrenamiento de los seres humanos. Con todo, hay una diferencia entre entrenar y domesticar. Para entrenar es necesario tener un entrenador. Pero no hay un entrenador de seres humanos. El entrenador se dedica a lo animal como mera vida, ahí donde no hay sujeto.

Más allá de la idea de "sujeto" domesticador de hombres, existe esta cultura que reproduce patrones biológico-espirituales de humanidad en los que la diferencia entre ser humano y ser demasiado humano se pierde. El superhombre tensa el proceso de domesticación. Es necesario que el proceso de domesticación sea lo que el humanismo trató de recobrar con la gramática, el lenguaje, la alfabetización y las escuelas. Los humanistas pusieron la mirada en los procesos de domesticación.

Sin embargo, no es suficiente contar con un proceso de domesticación por medio de la educación y la alfabetización. Al aceptar que la educación humanista promueve la domesticación, Nietzsche quiere que admitamos que hay un poder detrás del poder. El poder de un grupo selecto de lectores y de aquellos que no pueden leer.

En un sentido antropológico, debemos diferenciar entre los animales que son capaces de leer y escribir y los animales que no pueden hacerlo. Como resultado, hay hombres que crían a sus compañeros y hombres que son sirvientes. Esto es así, puesto que hay una diferencia entre vivir en casa amando a los otros y vivir en casas deseando ser amado por los otros. Querer ser amado es la voluntad de ser un objeto. Ser un sujeto selecto, un hombre selecto y único, significa no necesitar amor. En la actualidad, los hombres son más susceptibles de amar que de ser amados. Hay una emergencia de la subjetividad que supera a la objetividad. Para ponerlo con otras palabras, el arribo de la subjetividad es preferible a la costumbre de aceptar ser objetos usados por los otros. El paso adelante es el surgimiento de hombres que no aceptarán ser objetivados por nadie. Esta es 
la razón por la que Sloterdijk habla del hombre letrado, de la gente selecta, como emergencia de la subjetividad de gente que defiende el hecho de ser sujetos en lugar de cosas u objetos. Sin embargo, esta idea de un sujeto que domina a otros da lugar a la violencia. Vivimos en una sociedad violenta, y por lo mismo, vivimos en ciudades violentas.

Dice Sloterdijk:

Un código de esta clase también cambiará retrospectivamente el significado del humanismo clásico, ya que abriría el hecho notable de que la humanidad no consiste en una amistad hombre a hombre, sino que también implica —explícitamente- que el hombre representa la violencia más extrema. ${ }^{10}$

De acuerdo con esta idea, la política es el arte de la domesticación como proceso violento por el que los hombres subjetivos gobiernan a los sirvientes. Los políticos, en el mero sentido nuclear de ser gobernantes del Estado, poseen una carta magna pastoral (la constitución, el código de honor, el código de reglas) que da lugar a la vigilancia política. La idea es crear gente obediente para un Estado en sentido estricto; adaptar a la gente al Código nuclear de modo que el Estado pueda ser gobernado por lectores selectos. El objetivo es someter a los hombres a normas y reglas civilizadas que puedan ser claras y transparentes para todos. El resultado será una sociedad de gente urbanizada. La estrecha relación entre urbanización y domesticación envuelve la idea política de un grupo selecto que actúa como pastor de la gente. El proceso de domesticación es en sí mismo violento. Actualmente, los hombres viven en parques, desplegando una tarea zoológica. La llamada reflexión política es una declaración de principios en torno a las reglas para administrar parques humanos.

Necesitamos un arquetipo del ser humano que sea adecuado al modelo ejemplar que todos los hombres deben reproducir. Las masas sometidas y obedientes representan la nueva domesticación del tiempo tardomoderno. La virtualidad, la velocidad y la violencia, constituyen el patrón de nuestras ciudades.

${ }^{10}$ Ibid., 71 . 


\section{Consideraciones sobre la ciudad enferma}

Hasta ahora, hemos visto que el humanismo trató de ser comprendido como el arte de enviar cartas. El humanismo era el amor por los otros en la distancia —dice Sloterdijk-. El humanismo fue el esfuerzo de hacer amigos con el objeto de tener una sociedad organizada y articulada. Sin embargo, vimos también que leer y escribir cartas, libros, llegó a ser una capacidad especial de aquellos que poseían el saber contra aquellos que no sabían nada.

Dice Sloterdijk que los hombres de letras y alfabetizados domesticaron a los iletrados y analfabetos. La sociedad se convirtió en un sistema de poder y control que buscaba crear un ser humano homogéneo. Masas haciendo lo mismo, masas viviendo de la misma manera. Empero, el poder tras el poder reveló la necesidad humana de la violencia como lo vio Nietzsche cuando dijo que la educación es un medio para controlar a las masas que ejercían el poder. La virtud es la adecuación de la conducta a las reglas de los hombres selectos. Más allá del humanismo tiene que haber una aceptación de la dominación como modo de vida.

Heidegger sostiene que los humanistas controlan a los hombres, siguiendo a Nietzsche, dado que han olvidado el ser. Los hombres que gobiernan han olvidado ser pastores del ser. En silencio, los hombres hablan. Y los hombres viven en la casa del ser, esto es, en el lenguaje. Sin embargo, vivir en el lenguaje significa ser capaz tanto de leer como de escribir. Regresamos de nuevo a la diferencia entre los hombres selectos y los hombres domesticados. Ser político significa vivir bajo las reglas de los parques zoológicos humanos.

\section{Síntomas de una ciudad enferma}

Byung-Chul Han habla acerca de la era del vacío. ${ }^{11}$ El hombre no es maestro de otro hombre. La relación de maestro-sirviente (amo y esclavo) no es válida ya. El hombre se ha convertido en amo y esclavo de sí

${ }^{11}$ Las reflexiones que siguen se apoyan en el pensamiento de Byung-Chul Han. Al respecto, véase: La sociedad del cansancio (Barcelona: Herder, 2013); En el enjambre (Barcelona: Herder, 2014); La sociedad de la transparencia (Barcelona: Herder, 2015). Véase también: 
mismo. Trabaja mucho y se explota a sí mismo más que nunca en la historia. El propósito de la vida es llegar a ser eficiente, productivo, confiable, de modo que pueda hacerse de tantos bienes como sea posible. Acumular bienes es parte del capitalismo salvaje de nuestros días. La sociedad positiva es una sociedad donde una persona siente que puede tener lo que quiera. No hay nada en la vida que un hombre no pueda alcanzar. Así, el otro es un mero obstáculo a la satisfacción de los objetivos personales.

En la sociedad positiva, la negatividad del otro, la otredad, se destruye. La sociedad se convierte en una sociedad anerótica. Una relación erótica comienza aceptando la otredad del otro, de manera que se ama al otro que lo niega a uno mismo. En la relación negativa del erotismo uno debe enamorarse del otro en su otredad. Enamorarse significa literalmente caer en el ser del otro. Así, uno vive tratando de ponerse a sí mismo en el lugar del otro. En la sociedad del rendimiento el amor es reemplazado por la pornografía. Todo se muestra, todo está ante los ojos a través de las redes sociales: Facebook, Instagram, WhatsApp, donde uno pone una fotografía en el "muro", muestra su vida, proporciona información. Uno se vuelve visible a los otros. Ese es el hecho de la pornografía: mostrarse sin dejar nada oculto al misterio. Es tan evidente lo que se exhibe que nada es misterioso. La dimensión escondida del secreto se rompe. La otredad desaparece no solo en la medida en que yo soy un ser existente único, sino también en la medida en que yo veo todo lo que yo quiero sin dejar nada a la esfera privada del mundo del otro. No hay ya un sentido de la privacidad. La distinción entre público y privado no se produce más.

Han dice que en esta sociedad del rendimiento, la sociedad positiva, todo es transparente, ya que la mera esencia del ser del otro está a la vista. Hay tedio y aburrimiento en la sociedad, un sentido de fatiga. Fatiga de hablar a los otros. Fatiga de compartir el tiempo con los otros. Los seres humanos viven aprisa. La velocidad de la vida cansa tanto que el tiempo se diluye. No hay más contemplación del ser y no hay silencio. El ruido inhibe la capacidad de hablar y escuchar.

José Manuel Orozco Garibay, La fractura social. Un estudio del pensamiento de Byung-Chul Han (México: Editores de Textos de Autores Mexicanos, 2016). 
Rendimiento, fatiga, positividad, pornografía, transforman el sí mismo (self) en una máquina de datos. El sí mismo es un mero número, un número de seguridad social, una contraseña (tantas contraseñas como pueda haber: una para desbloquear el teléfono, una para conectarse en el cajero automático, una para ingresar al gimnasio, un número o clave de profesor, un número de cuenta bancaria, una clave de cliente, al infinito). Sufrimos entonces la red entrecruzada de relaciones impersonales en la que el otro no importa (su historia es irrelevante). Uno cumple su papel de acuerdo con el escenario en el que uno despliega sus habilidades. Prevalece un sentido de la vida programada sin una narrativa que articule los hechos. El momento fáctico se vive como si se tratase solamente de algo que ocurre: un simple acontecer. Pasar de un suceso a otro, y a otro, con una velocidad inaudita y sin pausas, hace imposible que haya un discurso del pasado, un sentido del presente y un proyecto hacia el futuro.

Marcel Proust escribió su gran obra $A$ la recherche du temps perdu ("En busca del tiempo perdido"), publicada en siete partes entre 1913 y 1927. En una de las escenas, Marcel recuerda el olor y el aroma de una magdalena que le recordó a su madre cuidándolo de niño, enfermo, allá en Swan. El recuerdo del aroma abrió el camino de su niñez, el sentido de la articulación total de las cosas que fueron revividas dentro del recuerdo de haber comido y olido el aroma de una magdalena. La necesidad de narrar el suceso, el instante, remite a una distancia enorme de tiempo. Va hasta la infancia para dar sentido a lo que vive, a quién es, a lo que era, desde el aroma de una magdalena. Hoy, en cambio, uno no tiene tiempo, uno carece de discurso, narrativa, y sentido del pasado.

En la sociedad positiva, el sentido del aroma del tiempo está perdido. El ser ha sido olvidado. Esa es la razón que explica por qué el hecho de vivir aprisa, apurado, hace imposible la contemplación. La vida activa se impone a la vida silenciosa. Lo activo mata el silencio. Uno va de un punto a otro olvidando a los otros. El narcisismo es el lugar del ser humano. Todos somos narcisistas en nuestros días. Al final, la pérdida de la concentración y la contemplación en la era de la velocidad da lugar a la despersonalización del hombre. La sociedad enferma actual es la sociedad del egoísmo, del individualismo, del narcisismo y de la 
muerte del lenguaje. La vida en la ciudad es una vida salvaje de átomos sin conexiones profundas entre ellos.

\section{Era digital}

La era digital aísla a la gente. Al mismo tiempo, es una era que produce masas de gente uniformada. Así, el respeto al otro se pierde, ya que el otro está ausente. El otro solamente aparece como mensaje en una pantalla, es una imagen, una mera idea en el espacio de la red. Aunque uno usa la red como medio para decir algo a otra persona, el rostro del otro está perdido. Byung-Chul Han dice que en el rompecabezas de la red digital no hay una masa porque no hay alma, no hay espíritu. El enjambre está hecho de individuos aislados.

La masa se constituye de manera diferente al mero enjambre. Los individuos se fusionan en una nueva identidad de manera que ellos pierden una identidad singular y un perfil propio. Un nuevo espíritu o alma se fusiona homogéneo en la masa cerrada sobre sí misma. Pero en el enjambre el alma no existe. Los individuos reunidos en el enjambre simplemente se suman al grupo sin compartir un espíritu común. Así, en el enjambre no hay un propósito común. No hay una voz que hable por la masa. Dado que estamos en el enjambre, vivimos el ruido, el estado de la hipocresía en el que el hombre hace público todo por medio de su ser homo digitalis, pero la vida privada permanece oculta.

Un hombre digital se presenta a los otros como anónimo, no es nadie en particular. Sin embargo, en el enjambre digital no existe un propósito común. La masa es muy diferente porque en ella los trabajadores en una marcha tienen una causa, un objetivo, un propósito. Mientras que la masa es sólida, el enjambre es volátil.

\section{La ciudad está enferma}

Vivimos concentrados en lugares urbanos donde millones coexisten. La comunicación entre las personas es nula. No hay tiempo para hablar con los demás. Todos vivimos aprisa, yendo de un lugar a otro. No hay tiempo 
para contemplar, para estar en silencio, para abrirse al ser. Al contrario, cada uno vive explotándose a sí mismo en la necesidad de producir más, acumular más, ser exitoso de acuerdo con las normas capitalistas. Nos hemos vuelto seres domesticados. Obedecemos las reglas y normas del zoológico donde vivimos.

Millones de coches nos rodean, entre avenidas y periféricos padecemos un sistema de transporte caótico. En cada coche va una persona aislada. Nadie le habla a nadie. Estamos en medio de la contaminación y el ruido, de las advertencias, en calles "vigiladas" por policías, aparte de las cámaras que nos vigilan, amén de los asaltantes y los balazos por todos lados. Una infracción aguarda siempre a la espera de castigar a alguien.

En el trabajo no falta una computadora, internet, correos que desfilan unos tras otros. Teléfonos, obligaciones, reuniones, juntas bobas con los jefes, instrucciones de sentido autoritario, celulares inteligentes que separan aún más a las personas. Podemos ver a cuatro personas sentadas para desayunar en un restaurante (papás e hijos), pero cada uno está escondido o perdido en la pantalla idiota de su teléfono, y no comparten nada al compartir el desayuno.

Los jóvenes viven desesperados, deprimidos, ansiosos, con expectativas muy altas que nunca pueden satisfacer. La brecha entre la demanda y la satisfacción es la frustración. La ciudad separa a los que tienen dinero y educación del enjambre de la gente ineducada. Diferenciamos entre los que mandan en la ciudad y los que sobreviven realizando trabajos a cambio de salarios miserables. Todos nos convertimos en máquinas ocupadas. La idea es rendir, estar calificado, ser capaz de hacer lo que sea con tal de sobrevivir en medio de una competencia salvaje.

En este sentido, en la ciudad, Eros está muerto. El narcisismo es una actitud constante que forma parte del ser de todos. Cada quien vive para sí mismo, pero no en el sentido social de compartir un alma dentro de la masa. Incluso si tenemos muchas iglesias, congregaciones, organizaciones sociales, todas forman parte del poder de algunos grupos que controlan a otros. Un grupo pequeño y sofisticado de ricos y letrados trata de controlar a los domesticados imponiendo un fuerte sentido de culpa en la masa domesticada. El resultado es la obediencia, la masa 
humana uniforme y obediente de máquinas acostumbradas a obedecer. Ese es el camino para parecer virtuoso y así ser visible.

En las sociedades positivas, no hay tiempo para ver al otro. Tampoco hay tiempo para escuchar la narrativa del otro. Las historias son prescindibles. No somos sino un número en la serie de las contraseñas que nos representan. La estrecha conexión entre pasado-presente-futuro también se pierde. Nadie se preocupa por los problemas de nadie en la ciudad. La violencia está presente en todas partes; reglas en la escuela y en el trabajo. Reglamento de tráfico; reglamentos para entrar a la ciudad. Los extranjeros son vistos como invasores potenciales. Todas estas reglas hacen que la vida sea miserable.

En Ciudad de México viven ocho millones de personas. La ciudad tiene cinco millones de coches. El metro tiene diecinueve líneas por las que se trasladan cinco millones de personas al día. Todos los días se despiden en la atmósfera más de 4000 toneladas de gases tóxicos. La violencia es lo usual. Y dado que todos viven metidos en sus teléfonos inteligentes (se puede comprar un teléfono para gente pobre o se puede optar por un iPhone caro para que el estatus sea evidente). Hay millones de líneas telefónicas del ámbito virtual. El sistema de distribución del agua es complejo, no hay mapas de la red de agua potable. La ciudad de México pierde cuatro metros cúbicos por segundo de la red del sistema de agua. Los viajes de un lugar a otro toman horas. Un estudio muestra que una persona pasa al menos dos horas diarias en su coche, detenida en el tráfico. La división entre la gente con dinero y las llamadas "ciudades perdidas" en los alrededores de la zona urbana, constituyen el núcleo del miedo. Asesinatos, secuestros, tráfico de drogas a pequeña escala, determinan el curso de la vida diaria en la ciudad. Así, el miedo es habitual, y habitual o normal es no sentir ya miedo, puesto que la gente da por sentado que puede ser el caso que se pierda la vida en cualquier momento. Uno puede ser secuestrado, robado, insultado en cualquier momento al conducir o caminar. Es posible ver hermosos y enormes edificios al lado de una plaza comercial de lujo como Santa Fe, y a la izquierda, apenas cruzando un puente, hay un asentamiento miserable de medio millón de personas en la miseria. Las chabolas de la gente miserable proporcionan sirvientes y trabajadores a las corpo- 
raciones millonarias, a escuelas de gente acomodada, pero también son los limpiaparabrisas de las esquinas de las calles en todos lados, los que empacan bolsas del supermercado, los que cuidan coches chiflando, los que lavan baños o limpian pisos, los porteros, guardaespaldas o escoltas, personal de mantenimiento. Hordas de vendedores callejeros saturan las calles en los tianguis, en el centro de la ciudad, en las periferias, o en las avenidas elegantes.

En la ciudad enferma, el enjambre produce gente enferma. Gente afectada con el síndrome de la decadencia (narcisismo, amor a la muerte, fijación simbiótico-incestuosa), como afirma Erich Fromm al hablar de la necrofilia y la violencia como opuestas a la biofilia. ${ }^{12}$ Los síntomas son: ansiedad, depresión, despersonalización, indiferencia, egoísmo, un sentido de amor por la destrucción de los sentimientos a favor de la vida, aburrimiento y fatiga. El choque entre clases, la división social, la ausencia de comunicación, el abuso constante, la corrupción y la impunidad, conforman el miedo pánico de vivir en la ciudad sin sentido.

En la ciudad de Dallas he podido percibir largas distancias. Sin un coche es casi imposible ir de un lugar a otro. Todo mundo tiene prisa. Casi no hay tiempo para hablar con los demás. Se requiere cita para poder platicar algunos minutos con un colega o autoridad y se tiene que ser conciso y veloz. El rendimiento debe probarse todo el tiempo. Hacer dinero es la condición central de una vida cotidiana cara. El sistema de transporte público es casi inexistente. La distribución de los condados implica que se tiene que tener tiempo para trasladarse de un condado a otro. Las personas se reúnen por momentos breves, comen el almuerzo y corren como hormigas.

Es un mundo tecnológico tan avanzado que la vida se ha vuelto esencialmente digital. Los latinos tienen miedo pues viven en condados urbanos como ilegales (en Irving eso se aprecia al hablar con ellos). El bello centro de Dallas está vacío el fin de semana, y los enormes edificios del poder son torres de vidrio fantasmales donde solamente hay un parque artificial rodeado de restaurantes carísimos. Ahí se refugian los pobres para pasar un domingo bajo calores sofocantes.

${ }^{12}$ Erich Fromm, El corazón del hombre (México: Fondo de Cultura Económica, 1985). 
Las universidades no están conectadas entre sí. El intercambio entre ellas es raro. Eso ocurre igualmente en Ciudad de México. Como resultado de todo esto, estamos en una ciudad enferma. En ciudades enfermas. Podría ser que, de acuerdo con Sloterdijk, nos hayamos convertido en gente que no lee y que no escribe, domesticada en parques zoológicos más o menos ordenados. Puede ser que el humanismo esté muerto y, en cualquier caso, podemos dividir la ciudad en los que son letrados y los otros.

De acuerdo con Han, estamos vacíos. Somos competitivos, pornográficos, transparentes, rendidores, autoexplotados, aneróticos, digitales en la era de los grandes datos. La ciudad enferma necesita nuevas transformaciones. El traspaso de la ciudad deshumanizada a la ciudad humana donde los humanos cuenten sus narrativas, dispongan de tiempo para la contemplación, posean un sentido de naturaleza, tengan tiempo para los otros haría posible dejar el coche y caminar.

En el caso de Ciudad de México, estamos en el límite. O cambiamos o colapsaremos. 